International Journal of Engineering \& Technology, 7 (1.5) (2018) 249-252
International Journal of Engineering \& Technology
SPC
Website: $w w w . s c i e n c e p u b c o . c o m / i n d e x . p h p / I J E T$
Research paper

\title{
A Study on graph with Desmos through Ict in diploma in elementary education of tamil Nadu state board
}

\author{
P.Charles Paul ${ }^{1 *}$, G. Thulasi ${ }^{2}$ \\ ${ }^{1}$ Lecturer in Mathematics, District Institute of Education and Training, Lawspet, Pondicherry. \\ ${ }^{2}$ Lecturer in Mathematics, Department of School Education, Government of Pondicherry. \\ *Corresponding authorE-mail: charupaul8@gmail.com
}

\begin{abstract}
This paper aims at bringing out the skill based learning outcomes in teaching learning process specific to psychomotor domain through ICT's based on New Educational Technology 2013. The present study intends to apply the Desmos software to teach the Linear Graph chapter in Diploma in Elementary Education (D.El.ED) of Second year in Tamil Nadu State. It explains the teaching strategies, i.e. visualization of graphical structure with the above module. Desmos gives hands-on experience to understand the mathematical, Graphical concepts. It also aims for an extended study on Algebra, Statistics and Geometry in the second year source book prescribed for the (D.El.ED) Course of Tamil Nadu State Board.
\end{abstract}

Keywords: ICT Education, Desmos, Graphs.

\section{Introduction}

In the pre-technology education context, the teacher is the dispatcher or the source, the educational material is the information or message, and the student is the beneficiary of the information.

UNESCO considers that ICTs can donate to universal access to education; equity in education, the delivery of quality learning and teaching, teachers' skilled development as well as to improve education management, dominance and administration provided with the right mix of policies, technologies and capacities are in place.

UNESCO takes an ample approach to ICTs in education. It is through the Organization's traverse oral Platform that it focuses on the joint work of the Communication and Information, Education and Science Sectors where the issues of entrée, insertion, equity and quality in education can be addressed Digital technologies are ubiquitous in media, government, commerce and education. In $21^{\text {st }}$ century, the present Educators need to be knowledgeable and critical users and creators of digital technologies. It focuses on the role of the digital world for children and emphasizes the grave knowledge and skills necessary for safe, responsible and principled use of ICTs in learning and teaching. The unit also supports student to select and use digital technologies to augment their own learning.

\section{Need and importance of the study}

The importance of revelation in mathematics, graphs are powerful because they allow students to visualize mathematical concepts (Battista \& Clements, 1991). From this view point, graphs are similar to other representation such as pictures, images, and diagram. However, graphs are even more powerful because they can also provide students with visual representation of mathematical relations, functions, and their properties .According to Leinhardt, Zaslavsky, and stein (1990), the introduction of graph represents an important landmark in the middle school mathematics curriculum. Using graph to represent functions constitute "one of the earliest point in mathematics at which a student uses one emblematic system to expand and understand another (e.g., algebraic functions and their graphs, data pattern and their graphs, etc.

Most prior studies on graphs have focused on the difficulties students encounter when interpreting and/or producing function graphs (see review by Leinhardt et al., 1990). For example, students tend to interpret time/distance graphs as descriptions of the shape of the terrain walked (Kerslake, 1981) and focus on secluded points instead of focusing on intervals, the shape of the graph, and the functional relationship between two variables (Bell \& Janvier, 1981). Additionally, students often fail to relate the shape of the graph of a function to its symbolic-algebraic version.

Such difficulties might be moderately due to students' limited experience with function graphs, which tend to be introduced rather late in the curriculum (commonly no earlier than in 6th grade) and dissociated from the teaching of algebra as rules for solving equations (Yerushalmy \& Schwartz, 1993)

Equations are then conceived as comparisons between two functions. Switching from a traditional approach to a functions approach to algebra requires the preparation of teachers, as well as evaluating how this preparation may manipulate their classroom practice. In our review of the literature, we have found very few studies on how mathematics teachers use graphs to teach mathematics and no studies on how ICT impacts the way teachers use graphs in class, which is the focus of the present paper. 


\section{Objectives of the study}

The objectives of the study is to how to commence ICT in teacher education curriculum of Diploma in Elementary Education of the Tamil Nadu State Board

* To assimilate the different ways of teaching in Diploma in Elementary Education Second Year of Tamil Nadu State Board using the Dynamic online software Desmos

* To assess coordinate plane vocabulary: x-axis, y-axis, origin, quadrant, coordinate

* To perform graphing and identifying points on the coordinate plane

* To evaluate the improvement in mathematical psychomotor skills among Diploma in Elementary Education students

* To strengthen the mathematical concept of "LINEAR GRAPH" by showing suitable example in Diploma in Elementary Education of the Tamil Nadu State Board.

\section{Why Ict?}

The ICT Test Bed evaluation (Underwood 2006) provides substantiation that many teachers use ICT to support pioneering pedagogy. It states: "New technologies that provide a good fit with existing practices, such as interactive whiteboards are first to be entrenched, but others like video conferencing, digital video and virtual classroom environments are now being integrated, providing evidence of ongoing learning by the workforce. Training needs to be continued to support pioneering pedagogy." "Changes that take full recompense of ICT will only ensue slowly over time, and only if teachers continue to experiment with new approaches." ICT Resource will enhance the existing topic through some aspects of the lesson and tasks. For example, to teach the topic "GRAPH" Using the smart board the teacher presents the skill of drawing graphs in order to promote the topic in visualization sense will create interest in teaching and learning process. With the help of online tool like via Desmos the task of presentation is reduced and the role of student's participation is increased to understand the concepts. The only thing is that the teacher should be having enough knowledge and mastery to use the ICT tools Desmos.

\section{Desmos a blooming tool in ICT}

Desmos is a highly developed graphing calculator execute as a browser application and a mobile application. It can also be used in several different languages.

All grades math functions like sin, cos, tan, asin, acos, atan are supported free

signup:http://www.facebook.com/Desmos.org/twitter:http://twitter.c om/Desmos,youtube:http://www.youtube.com/Desmos.Desmos, http: //www.youtube.com/Desmosinc.Desmos .It prominence the students to investigate in Start Graphing. Graph functions, conspire data, evaluate equations, discover transformations, and much more.

\section{Complementary approach}

While using the ICT resource online software Desmos to motivate the pupils learning and it will reduce the burden of taking notes inside the classroom. Here this online software program teaches the graphical concept in a lively learning environment in order to create interest in mathematical concepts. All the approaches can augment realization skills, but the effect may be different. It will routinely develop the psychomotor skills in teaching and learning process. It encourages students to devise their own explanation and new learning experiences.

\section{Impact of ICT on student performance in higher education}

There is no standard definition for student performance. The customary come close to focus on realization and curriculum, how students value the courses and acquire their degrees or their marks. However, a more all-embracing definition deal with competencies, skills and attitudes learned through the education occurrence. The tapered description allows the inspection of the outcomes of any change in higher education, while the more prominent definition needs a more intricate tactic of inspection and a spotlight on the labour bazaar. The outcomes of education are mainly evaluated in the labor bazaar. The relationship between the use of ICT and student performance in higher education is not clear, and there are indistinct results in the text. Previous monetary research has failed to provide a clear harmony pertaining to the effect on students' achievement.

In the second year in diploma in elementary education course of duration two years of Tamil Nadu state, Teaching of mathematics books contains the ten units, of which the topic is linear graph teaching the above topic using the dynamic online software Desmos the fabulous performance of the teacher trainer is achieved by practicing the module regularly.

\section{Observation made during intervention}

Desmos is open source online software in teaching and learning process. In the modern day mathematical concepts it plays an imperative role in student's participation inside the classroom. It can be used to teach the 3D shapes, analytic geometry and calculus etc. This software is used in different platforms through online. It also gives practical experiences to the student inside the class room and develops the learning environment .It excite the psychomotor skills in mathematical concepts. In this study the most important topic is Linear Graph from the second year of Diploma in Elementary Education course of two years duration in the Tamil Nadu state board was taken in to consideration .Many abstract concepts have been clearly explained through concrete examples and diagrams. In particular construction of Linear Graph, Finding solutions of two linear equation through graph .In addition to that solving quadratic equation and finding solution with the help of this free online software Desmos.

\section{Mathematical visualization concept and analysis}

To draw a LINEAR GRAPH with the linear equation $\mathrm{y}=\mathrm{mx}+\mathrm{c}$. one has to open the online software Desmos by using the url:www.Desmos.com ,then we have to type the linear equation in the command bar with the format $\mathrm{y}=\mathrm{mx}+\mathrm{c}$. On conclusion of the above command when we click the play button by order of the command the required picture is drawn by the online software. The complete picture is in the form of video format and that should be easily understood by the learner. Similarly, we can draw various types of graph having different slope i.e $m$ and different $y-$ coordinates. In this situation the learner will see the variation of line in the graph and concludes that the line having different slopes, the direction of the line changes. In addition to that the learner learns how to draw quadratic graphs, parabolic graph, elliptical graph etc. It is important to mention that the method of drawing graph in the 
graph sheet is static and the learner learns the concepts in conceptual, but when we teach this concept through the online software Desmos it is easy to recognize the graphical idea very easily. In all the figures we can deduce all the values in order to get various graphical structures pertaining to Linear Graph, Quadratic Graph, Parabolic Graph etc .Similarly all the above figures can be drawn and shown in the following descriptive examples:

\section{Construction of linear graph in the form $\mathrm{Y}=\mathrm{Mx}+\mathrm{C}$ having different slopes and $\mathrm{Y}$-Intercepts and finding solution for it}

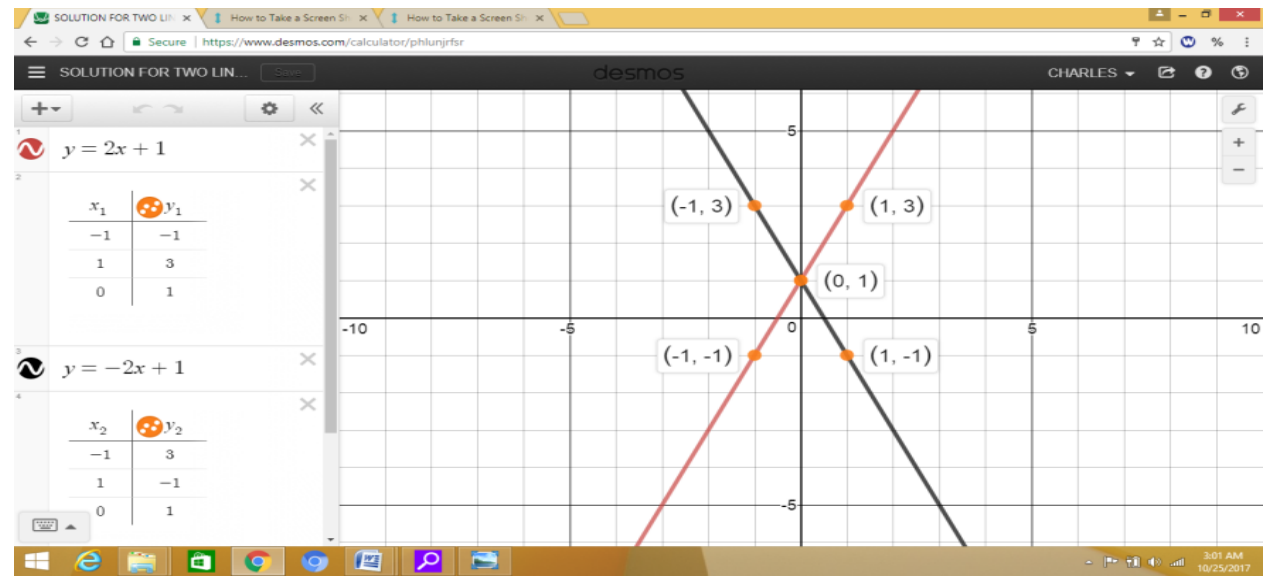

Fig.1:

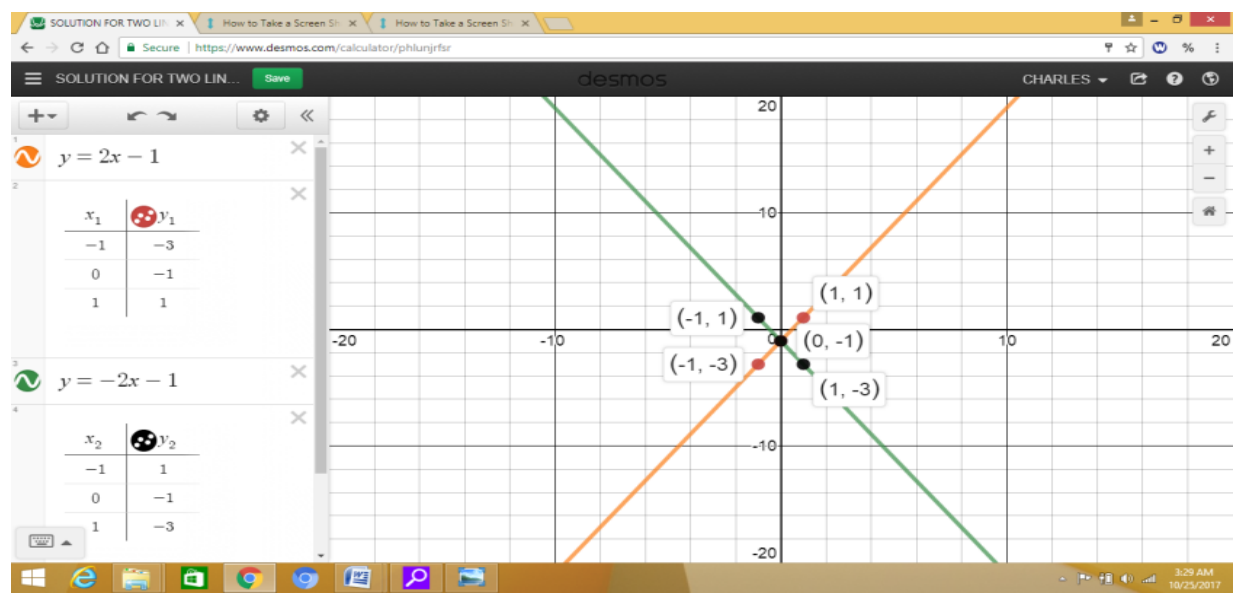

Fig.2:

\section{Findings}

On observation of all the annexed illustrations we can tabulate the required solution in the following table

\begin{tabular}{|c|c|c|c|c|}
\hline \multicolumn{5}{|c|}{ Table 1} \\
\hline SLNO & $\begin{array}{l}\text { EQUATION OF } \\
\text { LINEAR } \\
\text { GRAPH } \quad \mathrm{y}=\mathrm{mx} \\
+\mathrm{c}\end{array}$ & $\begin{array}{l}\frac{1}{2} \\
0 \\
0 \\
0\end{array}$ & 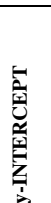 & $\begin{array}{l}\text { SOLUTION BETWEEN TWO } \\
\text { LINEAR EQUATION }\end{array}$ \\
\hline 1 & $y=2 x+1$ & $m=2$ & $\mathrm{C}=1$ & The intersecting point is $(\mathbf{0 , 1})$ \\
\hline 2 & $Y=-2 x+1$ & $\mathrm{~m}=-2$ & $\mathrm{C}=1$ & SOLUTION:(0,1) \\
\hline 3 & $Y=2 x-1$ & $\mathrm{~m}=\mathbf{2}$ & $\mathrm{C}=-1$ & The intersecting point is $(0,-1)$ \\
\hline 4 & $Y=-2 x-1$ & $\mathrm{~m}=-2$ & $C=-1$ & SOLUTION:(0,-1) \\
\hline
\end{tabular}

\section{Discussion along with implications}

A teaching method comprises the principles and methods used by teachers to facilitate students learning. These strategies are unwavering moderately on subject matter to be taught and to a certain extent by the nature of the learner. These traits are helpful to distill personality. Motivating and appreciating is a success which comes in a different shapes and sizes, therefore the teacher as a good scholar must categorize the required ICT tools to give the method of teaching in the fruitful manner. In this case the dynamic software Desmos was adequate to teach the curriculum and was appreciated by the students with poor background in rural areas.

\section{Conclusion}

In this finding and study the teacher should come with the different techniques and technology and the teacher should be the broad and open minded for the students but at the same time he has to motivate 
and create interest among the students in teaching and learning process. Mathematics being an abstract subject, the use of ICT tools gives significant relief in satisfying the students understanding in the concept. In this context teachers have to take up the challenges to create a new dimension in teaching mathematics in the topic "Linear Equation - Finding Solution", so that the objectives of the psychomotor skills of the students is attained. Hence the teacher has to master over the subject taught by utilizing this kind of online software available in the market and he should always think about to improve the teaching technique by learning the new technology, In order to develop the personality development of the student in the teaching learning process. It is also suggested that the similar study may be carried on the concepts of algebra and co-ordinate geometry in the second year Diploma in Elementary Education course of Tamil Nadu State Board.

\section{Reference}

[1] Battista, M. T., \& Clements, D. H. (1991). Using spatial imagery in geometric reasoning. The Arithmetic Teacher, 39(3), 18-21.

[2] http://mathvault.ca/Desmos-guide

[3] Text book for second year diploma in elementary education course of Tamil Nadu state board

[4] http://www.Desmos.com

[5] Rajesh, M., and J. M. Gnanasekar. \&quot;Congestion control in heterogeneous wireless ad hoc network using FRCC.\&quot; Australian Journal of Basic and Applied Sciences 9.7 (2015): 698702.

[6] S.V.Manikanthan and V.Rama"Optimal Performance Of Key Predistribution Protocol In Wireless Sensor Networks" International Innovative Research Journal of Engineering and Technology ,ISSN NO: 2456-1983,Vol-2,Issue -Special -March 2017.

[7] T. Padmapriya and V. Saminadan, "Inter-cell Load Balancing Technique for Multi- class Traffic in MIMO - LTE - A Networks", International Conference on Advanced Computer Science and Information Technology, Singapore, vol.3, no.8, July 2015. 